\title{
LAS PARADOJAS DE LA (IN)VISIBILIDAD. TRAYECTORIAS DE VIDA DE LAS PERSONAS TRANSMASCULINAS EN LA ARGENIINA CONIEMPORÁNEA.
}

\section{Mariana Álvarez Broz ${ }^{*}$ \\ Universidad Nacional de San Martín - Argentina}

Resumen: Este artículo abordara las trayectorias de vida de las personas transmasculinas en la Argentina contemporánea. En ese marco, el propósito es mostrar las paradojas que atraviesan a estas personas en su proceso de visibilización, con el objeto de problematizar la relación entre igualdad-desigualdad. En este sentido, este artículo buscar complejizar la mirada "positiva" que existe sobre la visibilización de las personas LGBT, y reflexionar en torno de las particularidades, en términos de ventajas y desventajas, que acontecen en el caso específico de las personas transmasculinas. Este trabajo se interesa por las prácticas de visibilización en tanto tácticas (De Certeau, 1996) que los informantes ponen en juego en función de sus necesidades, en determinados contextos, y de acuerdo a las contingencias.

Palabras clave: agencia, desigualdad, personas transmasculinas, visibilidad.

Abstract: This article will discuss the life trajectories of male trans people in contemporary Argentina. In this context, the purpose is to show the paradoxes that trough these people in their process of visibility, in order to discuss the relationship between equality and inequality. This line intends to review the "positive" look that exists on the visibility of LGBT people, and reflect on the particularities in terms of advantages and disadvantages that happens in the specific case of male trans people. This paper is concerned on visibilization practices as tactics (De Certeau, 1996) that subjects develope according to their needs, in certain contexts, and according to the contingencies.

Keywords: agency, inequality, male trans people, visibility.

\footnotetext{
* Doctoranda en Sociología. Contacto: mariana.c.alvarez@gmail.com
} 
Hablaría de minas y de fútbol a los gritos hasta quedarme afónico. No levantaría la mesa ni aunque me pagaran, mantendría a mi mujer en su lugar y maltrataría a "los” travestis a los que deseo en secreto [...] Si yo quisiera podría transformar mi historia en olvido, mi cuerpo en cita, mi felicidad en el grado de concordancia que me devuelve el espejo. Podría dejar de ser trans y convertirme en un hombre, tan solo un hombre, parte del mismo mundo donde hombres $y$ mujeres reinan. Por supuesto que podría, si yo quisiera.

Pero no quiero.

Mauro Cabral (2007)

\section{Introducción}

El presente artículo forma parte de una investigación en curso sobre las representaciones y las experiencias de desigualdad que afectan a las personas trans $^{1}$ en la argentina contemporánea.

Sobre la base del trabajo de campo iniciado en marzo de 2013 en el marco de mi investigación doctoral, en este texto me propongo analizar las trayectorias de vida de las personas transmasculinas ${ }^{2}$ y las paradojas que atraviesan su proceso de visibilización, con el propósito de problematizar la relación entre igualdad-desigualdad.

\footnotetext{
Entiendo por personas trans a aquellas que, en términos generales, producen una ruptura de la norma sexo-genérica no identificándose con el sexo asignado al momento de nacimiento y/o con el binario femenino-masculino.

2 Usaré la categoría transmasculina o transmasculinidades para hacer referencia a aquellas personas que habiendo nacido como personas biomujeres, en el sentido que le otorga Preciado (2008) se identifican (y construyen su identidad) -aunque con matices y diferencias- con el género masculino. Esto no implica que este término opere como un compartimiento estanco y cristalizador de identidades, o que desestime otros apelativos a través de los cuales las personas transmasculinas puedan referirse a sus propias vivencias. De hecho, es dable aclarar que mis informantes se autoidentifican de maneras diversas: hombres trans, varones trans, chicos trans, hombres, masculinidades trans, por mencionar las más recurrentes. En cada caso, los iré presentando de acuerdo a las formas de identificación que cada uno se autoadjudica, aunque yo me referiré a ellos -en sentido general- a través de la categoría transmasculinidades con el propósito de, por un lado, evitar privilegiar una de esas formas de identificación por sobre las otras, y, por otro lado, para acentuar mediante el prefijo trans ese proceso de subjetivación.
} 
El objeto de este artículo es complejizar la mirada "positiva" que existe sobre la visibilización de las personas $\mathrm{LGBT}^{3}$ y reflexionar en torno de las particularidades, en términos de ventajas y desventajas, que atraviesan a las personas transmasculinas. Si bien reconozco la importancia que han tenido las políticas de la visibilidad para el movimiento de la diversidad sexual (Bellucci; Rapisardi, 1999; Meccia, 2006; Moreno, 2008, entre otros) no puede soslayarse que la relación visibilidad-invisibilidad presenta no sólo modalidades distintas entre las y los sujetos de la diversidad sexual (Moreno, 2008) sino también incluso dentro del universo trans.

Partiendo desde una perspectiva relacional de la desigualdad (Reygadas, 2008) que, de manera dialéctica, atienda tanto los mecanismos que la generan como aquellos otros que la cuestionan, limitan o subvierten, daré cuenta de las experiencias que ubican a las personas transmasculinas en posición de desventaja social como así también de aquellas prácticas agentivas (Ortner, 2016) que ellos ponen en juego para contrarrestar y modificar esas experiencias desigualadoras.

Con el objetivo de abordar las trayectorias de vida de las personas transmasculinas, adopté un enfoque biográfico ${ }^{4}$ que me permitiera poner en diálogo de manera dialéctica la historia individual y la historia social, a partir del estudio de las experiencias de vida de las personas trans. En particular, trabajé con el método conocido como "relato de vida" (life stories), ${ }^{5}$ en su variante interpretativa comprensiva (Bertaux, 2005) con el propósito de identificar y describir los "índices", entendidos como aquellos aspectos que son reconocidos tanto por los autores del relato como por el investigador como hechos que han marcado la experiencia de vida de estos sujetos.

3 Con estas siglas me refiero a lesbianas, gays, bisexuales y personas trans.

4 El método biográfico constituye una manera - entre otras- de hacer sociología desde principios del siglo XX. Fue en el marco de la Escuela de Chicago, y a partir de la década del '20, que proliferaron los estudios de los relatos y las historias de vida y los estudios de caso en obras pioneras como las de Thomas y Znaniecki (El campesinado polaco en Europa y América, publicada en 1918-1920) y, más tarde, el trabajo de Oscar Lewis (Los hijos de Sánchez, en torno de la pobreza, publicada en 1964). Después de la Segunda Guerra mundial, se impuso la hegemonía de la sociología norteamericana -con sus pilares en el método de encuestas y el funcionalismo parsoniano- sobre todas las otras formas de observación y de teorización (Bertaux, 1999).

5 Los "relatos de vida" se diferencian de "las historias de vida" en tanto implican un rastreo extenso y detallado de la trayectoria vital de la persona, al modo de un estudio de caso. De este modo, se selecciona una o algunas pocas personas las que se consideran prototípicas del tema que se pretende abordar.

Horizontes Antropológicos, Porto Alegre, ano 23, n. 47, p. 227-258, jan./abr. 2017 
En ese camino, me ocupé tanto de la dimensión "socio-estructural" como de la "socio-simbólica" (Bertaux, 2005); es así como al tiempo que me centré en la escucha atenta de los relatos y su posterior sistematización y organización, relevé datos en torno a sus condiciones socio-demográficas (nivel de estudios alcanzado, ocupación y fuente de ingresos, cobertura médica, etc.) en función del material estadístico disponible. ${ }^{6}$

Al respecto, y a pesar de la escasez de estudios que indagan sobre las personas transmasculinas en Argentina ${ }^{7}$ los datos arrojados por la "Primera Encuesta sobre Población Trans" (Instituto Nacional de Estadísticas y Censos, $2012)^{8}$-un estudio exploratorio y parcial realizado en la localidad de La Matanza de la Provincia de Buenos Aires- revela que en relación a la ocupación laboral el 35\% trabaja de empleado; el 55\% por cuenta propia; y el 10\% vinculado a la actividad religiosa. En relación a la salud, sólo el $18 \%$ se realizó algún tratamiento de hormonización y la mayoría de ellos lo hicieron sin ningún control médico. En el ámbito educativo, el 40\% afirma haber sufrido situaciones de discriminación de parte de sus compañeros por su condición trans.

Respecto de las técnicas de recolección de la información, las narrativas biográficas fueron obtenidas a través de la realización de entrevistas en profundidad con un tipo de contacto personal "cara a cara" y de modalidad semi-estructurada y, en ocasiones, no estructuradas (o conocidas también como entrevistas abiertas), generalmente como complemento de la observación en campo, privilegiando el continuum de libertad concedido al/la entrevistado/a (Marradi, 2012). Éstas tuvieron como propósito no sólo la obtención de información referida a la sucesión de acontecimientos vividos sino también a

6 Es dable considerar -y un dato a tener en cuenta- que dentro de la comunidad trans, las personas transmasculinas son las que menos atención han recibido por parte de los investigadores, motivo por el cual la existencia de estudios sobre sus condiciones de vida es muy escasa.

7 Los estudios sobre personas trans en la Argentina comenzaron a desarrollarse hacia fines de los años ' 90 . Todos ellos fueron de índole cuantitativo sobre la base de encuestas que aplicaron las organizaciones sociales trans en alianza con algunos/as investigadores sociales. Si bien todos estos estudios fueron exploratorios y parciales (dado que se aplicaron sólo en algunas provincias o en ciudades de gran concentración poblacional del país) permitieron conocer características sociodemográficas y condiciones de vida de la población trans femenina, teniendo en cuenta que hasta el día de hoy no existen datos oficiales ni sistemáticos sobre este grupo social. Sin embargo, las personas transmasculinas casi no han sido incluidas en estos estudios.

8 Informe de la "Prueba Piloto de la Primera Encuesta sobre Población Trans" llevado a cabo por el Instituto de Estadística y Censos con la colaboración del Instituto contra la Discriminación, la Xenofobia y el Racismo. Se realizó en el partido de La Matanza entre los días 18 al 29 de junio de 2012.

Horizontes Antropológicos, Porto Alegre, ano 23, n. 47, p. 227-258, jan./abr. 2017 
la verbalización de una apropiación individual de la vida colectiva (Alonso, 1998). ${ }^{9}$ Las entrevistas fueron realizadas en su totalidad a través de la técnica conocida como bola de nieve, siendo fundamental, en esta investigación acceder a los informantes a través de otra persona trans. ${ }^{10}$

\section{Ser uno más}

La primera vez que tuve la oportunidad de conversar con Damián ${ }^{11}$ fue en su casa de estilo $\mathrm{PH}^{12}$ ubicada en el barrio porteño de Colegiales. Me recibió en un pequeño patio cubierto de plantas tupidas donde desembocaban todas las habitaciones de la casa, incluso la cocina y el baño. El aire que emanaba de un viejo ventilador nos refugiaba de las altas temperaturas de esa tarde calurosa de diciembre de 2013, año que comencé mi trabajo de campo con personas trans.

Mientras me contaba sobre su carrera teatral y la obra que estaba por estrenar señaló algo que luego escuche en reiteradas oportunidades entre mis informantes transmasculinos. Me confesó que él podía haberse dedicado a escribir guiones sobre otras problemáticas o hacer su experiencia como director de teatro sin dar cuenta de su condición trans porque, sin duda, pasaría inadvertido. Sin embargo, no lo hizo.

Muchas personas consideran que las personas transmasculinas tienen esa ventaja: transitar como hombres sin más. Pese a ello, Damián elige visibilizarse como una persona trans. Tiene 30 años, es de contextura chica, y se asumió como un hombre trans - tal como él se define- hace dos años cuando conoció a Luana, una mujer transexual con quien actualmente vive en pareja.

9 Las entrevistas se realizaron a un total de diez personas transmasculinas que tenían entre 18 y 30 años y que residían en el área metropolitana de Buenos Aires.

${ }^{10}$ La decisión y elección de esta técnica responde a la importancia -y a la necesidad- de llegar a las personas trans a través de otra persona trans (más allá de que fuera amiga/o, conocida/o, o que sólo lo/a hubiera visto/a una vez en la vida) debido a las reiteradas situaciones de estigmatización y discriminación sufridas por las comunidad trans en general, y las transmasculinidades en particular.

${ }^{11}$ El nombre de los informantes fue modificado para preservar su identidad.

${ }^{12} \mathrm{La}$ abreviatura PH refiere al tipo de Propiedad Horizontal, y consiste en un régimen que organiza la forma en que se divide un inmueble y la relación entre los propietarios del lugar. En la jerga de venta y compra de propiedades se utiliza para hacer alusión a un tipo de vivienda que incluye un porcentaje de propiedad sobre los elementos comunes de todos los propietarios del terreno en cuestión.

Horizontes Antropológicos, Porto Alegre, ano 23, n. 47, p. 227-258, jan./abr. 2017 
Desde chico se identificó con lo masculino pero sus dos hermanas mayores lo instaban a que "actuara como mujer" para que no lo encasillaran como un loco.

Era en la casa de su primo Gastón donde él desplegaba y vivía con naturalidad su masculinidad: jugaban a la pelota, intercambiaba autos de colección y practicaban juegos de lucha con el cuerpo de igual a igual. "Gastón lo percibía, lo sabía, comprendía que de alguna manera era como él, pero al igual que a mi le faltaban palabras para nombrarme".

Cuando tenía doce años, su tía lo llamó aparte y le dijo que le estaba cambiando el cuerpo y que por ese motivo no podía seguir mostrándose con el torso desnudo ante los demás porque muy pronto iba a desarrollarse y convertirse en "señorita".

Ese señalamiento por parte de su tía lo recuerda como un punto de inflexión: "me desmoroné, me deprimí, sentí mucha tristeza", porque andar en cuero implicaba para Damián "romper el corset social que suponía ese binario sexual en el que no hay cabida para otra expresión de género" (Lacombe, 2013, p. 200).

A partir de entonces, y sobre todo cuando su cuerpo comenzó a dar señales de aquello que él no quería ver ni exponer ante los demás, se replegó sobre sí porque le avergonzaba su "femenino"; salía lo justo y necesario a la calle - tan solo para ir y venir de la escuela- y cuando iban visitas a su casa se escondía en su cuarto para evitar que lo vieran y no salía hasta que se fueran.

Al respecto, Kimmel (1997) plantea que una de las características principales del proceso de construcción de la masculinidad es la "huida de lo femenino". Esto da cuenta cómo la construcción de identidades masculinas se produce de un modo relacional, es decir, no puede escapar a la lógica de las relaciones de género que estimulan ciertas prácticas al tiempo que señalan o proscriben otras vinculadas a la feminidad.

Aquellas masculinidades encarnadas en cuerpos que rechazan o resisten el proceso de feminidad obligatoria (Tron; Flores, 2013, p. 181) son relegadas al silencio y al ocultamiento que provoca el castigo social como consecuencia de haberse rebelado contra el destino del género o, más propiamente, contra el género (femenino en este caso) como destino (Tron; Flores, 2013), tal como lo experimentó Damián.

Algo similar experimentó Lucas. Él se autoidentifica como un varón y agrega lo trans dependiendo de las circunstancias. Creció en la ciudad de 
Quilmes junto a sus padres y a su hermano menor, quien fue el que más lo contuvo y lo acompañó durante su transición, proceso que comenzó hace siete años apenas terminó la escuela secundaria.

De chico pasaba mucho tiempo en la calle jugando con un grupo de amigos del barrio. Recuerda que le tocaban el timbre de su casa para invitarlo a jugar a la pelota a un descampado cercano, para ir a dar vueltas en bicicleta por la ribera del río de Quilmes, o para andar en el skate que le prestaba su hermano menor ya que él no tenía uno propio.

Ellos lo trataban como a uno más y eso hacía que él se sintiera aceptado, a gusto y querido tal cual era. Porque había algo que si bien no se ponía en palabras estaba implícito en la forma de vincularse: entre él y sus amigos no había diferencias, éstas aparecían cuando sus padres intervenían para denunciar que esa no era la manera de comportarse. Le recriminaban que siempre andaba con varones y que no tenía amigas con quien relacionarse. Y le marcaban cómo tenía que vestirse, caminar, pararse y qué posiciones no eran apropiadas para una niña, por ejemplo hacer pis parada y con la tabla del inodoro levantada o recostarse en el sillón con las piernas abiertas dejando entrever la bombacha.

La hipervisibilidad con la que se alumbraba ese cuerpo con un género que no corresponde normativamente a su sexo (Tron; Flores, 2013) y la tenacidad con la que se custodiaban sus modos de comportamiento por parte de sus padres principalmente pero también en la escuela fueron tornándose más rigurosas a medida que fue creciendo, y de alguna manera influyeron en su retracción y en su baja autoestima.

El hecho de "andar en cueros" y "hacer pis parado" son los dos gestos por excelencia que requieren vigilancia y control severo tras su ejercicio en libertad hasta que la voz de la reprimenda se instala con rigor, provocando vergüenza e inhibición (Tron; Flores, 2013).

Sobre infancias masculinas protagonizadas y encarnadas en cuerpos de niñas Tron y Flores (2013) plantean que la masculinidad se enciende con el sentimiento de "no encajar", de sentirse rara y ajena al mundo de las niñas, de engendrar bronca y frustración por prohibiciones y proscripciones dispares.

Una masculinidad que discurre de manera sigilosa con otros niños, se va tramando entre pares, donde la mayor conquista es ser considerado y tratado como un igual.

Esto pone en evidencia que la masculinidad no es un objeto dado que los machos de la especie "se disponen a vestir como si se pusieran un traje ya 
confeccionado", sino que se construye, se aprende y se practica en el torrente del devenir cultural, histórico y social (Faur, 2004, p. 52).

Varios autores (Badinter, 1993; Gilmore, 1994; Viveros; Cañón, 1997, entre otros) que trabajan sobre masculinidad coinciden en señalar que ésta requiere un proceso constante de afirmación, frecuentemente perfeccionado a partir de ciertos "rituales" que cada cultura marca a los varones como modo de iniciación (Faur, 2004, p. 64).

En otras investigaciones sobre transmasculinidades (Mendieta, 2016; Sennett, 2006) se identifica la primera vez que se cortan el pelo cortito como el inicio de su proceso de masculinización. En los relatos de Damián y de Lucas esto comienza a ensayarse, como vimos, en las actividades lúdicas "entre niños", ${ }^{13}$ en la medición de la fuerza y en los gestos de valentía expuestos en la lucha cuerpo a cuerpo, y en los comportamientos asociados típicamente a los varones como hacer pis parado o la preferencia de andar "en cuero". Estas prácticas reprobadas y sancionadas por el mundo adulto son compensadas, según el relato de mis informantes, por el gesto de reconocimiento y legitimación por parte de otros niños como sus pares.

\section{Masculinidades heterogéneas}

\section{Identificaciones}

A lo largo de mi investigación advertí que las personas transmasculinas expresan y experimentan su masculinidad de formas variadas e incluso cambiantes durante sus proceso de transición. Las formas de autoidentificación e incluso las maneras de interpretar y vivir la masculinidad son sumamente heterogéneas y flexibles, y esto da cuenta de la manera singular de concebir y apropiarse de lo trans. Pero sobre todas las cosas pone en evidencia las diversas formas en que ellos quieren (in)visibilizarse y ser percibidos por los demás.

Esteban tiene 22 años, y desde que nació vive en el barrio de Caballito. Se identifica como un hombre a secas, y está de novio con una compañera del colegio desde los veinte. De chico, cada vez que le preguntaban qué quería ser cuando fuera grande de manera deseante y contundente respondía: un varón.

13 Estas actividades lúdicas aunque están asociadas a las prácticas típicas de los varones no son exclusivas de ellos, dado que muchas niñas también las practican. 
Durante su niñez con quien mejor se entendía era con su hermano. Porque si bien se vinculaban a través de patadas y golpes de puño esa era la manera en que se sentía verdaderamente aceptado.

Esto no es de extrañar ya que la aptitud para el combate y el ejercicio de la violencia forman parte de aquellas prácticas en donde se afirma la virilidad masculina (Bourdieu, 1998). La tendencia de los hombres -en comparación con las mujeres- a manifestar comportamientos violentos, arriesgados o competitivos, basada en la demostración de superioridad y en la rivalidad como elemento central de las relaciones personales, guarda relación con un aprendizaje de género en consonancia con los valores tradicionales de la socialización masculina (Castells; Subirats, 2007).

Su paso por la escolaridad fue una "letanía" como él mismo lo define. En la primaria lo cambiaron dos veces de escuela porque sus padres consideraban que no se integraba con las chicas, y en la secundaria circuló por tres instituciones escolares diferentes ya que, además de repetir de año, no se sentía a gusto por el trato que recibía debido a su aparente homosexualidad.

Recuerda que la primera vez que se sintió atraído por una chica fue cuando estaba en tercer grado, y su confesión a otra compañera provocó la burla de sus pares y la preocupación por parte de la institución educativa, al punto de que citaron a sus padres para recomendarle tratamiento psicológico, y a partir de eso sus padres decidieron cambiarlo de escuela.

Recién en la adolescencia cuando su atracción por las mujeres se fue tornando una recurrencia se atrevió a contarlo a su familia quienes lo interpretaron y lo aceptaron como la manifestación de su homosexualidad. Sin embargo, él sabía internamente que lo relativo a su identidad no tenía que ver solamente con su preferencia erótico-amorosa por las chicas, pues había "algo más" que aún le provocaba malestar y que no se cesaba sólo asumiéndose como lesbiana.

Finalmente terminó el bachiller en un CENS ${ }^{14}$ donde había llegado por recomendación de un amigo quien le había contado que en esa escuela nocturna estudiaba una tal Sabrina "que había nacido como varón”. Fue allí la primera vez que se presentó como "Pato" y comenzó a ser tratado en masculino. En su relato identifica ese gesto y el hecho de recibir el nuevo DNI (con su

${ }^{14}$ CENS es la abreviatura de Centros Educativos de Nivel Secundario que permite a los adultos o adolescentes terminar sus estudios secundarios, dependiente del Gobierno de la Ciudad de Buenos Aires.

Horizontes Antropológicos, Porto Alegre, ano 23, n. 47, p. 227-258, jan./abr. 2017 
nombre masculino) como un click en su biografía: "me dieron la esperanza de que realmente podía ser la persona que deseaba desde chico".

También Facundo tiene en común con Esteban su paso por el lesbianismo, tal como ellos caracterizaron un momento particular de su proceso de transición. ${ }^{15}$ Sin embargo, su particularidad reside en que aunque se asume como una persona transmasculina prefiere ser identificada con el pronombre "ella"16 dado que se reconoce más como una "marica con plumas que como una torta chonga". El sentido de utilizar y apropiarse de lo transmarica tiene que ver con el hecho de distanciarse de la masculinidad hegemónica (Connell, 1995) y acercarse a una masculinidad femenina (Halberstam, 2008).

Para ella, identificarse de esa manera implica utilizar el lenguaje, en principio, para problematizar el binario obligatorio (hombre-mujer) y puntear una contradicción: mientras que llamarse Facundo le permite aludir a su masculinidad, el uso del pronombre 'ella' le permite, a su vez, referirse a su parte femenina. Y ser una persona trans, para ella, es justamente no ser ni hombre ni mujer, es sostener esa ambigüedad entre lo femenino y lo masculino.

Asimismo, referenciarse con el pronombre 'ella' y puntuar esa contradicción aparente con su imagen masculina es evitar "pasar desapercibido", es romper con la invisibilización propia de la transmasculinidad, es asumirse y mostrarse como una persona trans.

Interesada en la manera en que se trama el género en el lenguaje Wittig (1992) sostiene que es importante detenerse en el empleo de los pronombres personales porque, por un lado, constituyen la única instancia lingüística que designa y representa a los hablantes en el discurso y, por otro, porque van moldeando al género en el lenguaje, en su desplazamiento y en su devenir. Es decir que "el lenguaje ejerce una acción plástica sobre lo real" (Wittig, 1992, p, 105).

Es en ese marco que su propuesta filosófica-política apunta a destruir el género en el lenguaje (o al menos a modificar su uso) con el propósito de romper con la lógica dominante donde los hombres se han apropiado desde siempre de 'lo universal' y las mujeres han sido reducidas a 'lo particular'.

${ }^{15}$ La referencia al lesbianismo no es una caracterización propia sino más bien es una categoría de la que dieron cuenta mis informantes para aludir a un momento particular en su proceso de transición hacia la transmasculinidad.

${ }^{16}$ En este caso particular, me voy a referir a Facundo como "ella", respetando su pedido explícito de ser identificada de esta manera.

Horizontes Antropológicos, Porto Alegre, ano 23, n. 47, p. 227-258, jan./abr. 2017 
Y si bien Wittig dedica sus reflexiones y sus propuestas a erradicar la "marca de género en el lenguaje" porque entiende que afirma y reproduce la posición de subordinación de las mujeres, me interesa recuperar su idea no para suprimir esa marca que alude al género sino más bien para mostrar el potencial transformador que puede tener su uso en las identificaciones trans. Puesto que en el caso de Facundo el empleo del pronombre personal de una manera que contradice, desde una mirada heterocentrada, su imagen física y que pretende interpelar y generar una provocación en los otros le permite visibilizar lo invisibilizado. O, dicho de otro modo, señalar y poner el acento, en aquello que de otra manera hubiera sido pasado por alto: su condición trans.

Volviendo a su historia, Facundo nació y se crió en la ciudad de Neuquén en el seno de una familia numerosa: padre, madre, tres hermanas mujeres y su abuela paterna que siempre vivió con ellos. Desde su temprana adolescencia forma parte de un colectivo feminista de su provincia, espacio donde comenzó a hacerse preguntas sobre su orientación sexual y a experimentar su lesbianismo. Sus padres siempre se mostraron dispuestos a escucharla e incluso, eventualmente, a participar de las actividades y las jornadas de reflexión que organizaba su colectivo sobre los derechos y las estrategias de acción y resistencia de las mujeres y las lesbianas.

Sin embargo, no tuvo la misma recepción y contención cuando se asumió como una persona trans. Puesto que aunque sus padres son muy jóvenes (ambos tienen 45 años) y podrían caracterizarse como personas "abiertas" y "progresistas"17 (docentes sindicalistas, militantes por los derechos humanos, padres que criaron a sus hijos e hijas con mucha libertad según el relato de Facundo) cuando a los diecisiete años ella se identificó con la masculinidad su madre, en particular, quien reprobó su identidad trans le pronosticó que iba a tener una vida muy desgraciada. En ese contexto, y de acuerdo a su relato de vida, los primeros pasos de su transición trajeron aparejadas situaciones de conflicto intrafamiliar y de aislamiento de su grupo de pares, salvo por sus compañeras de militancia.

17 Dentro de la multiplicidad de interpretaciones posibles, tomo la definición que Raymond Williams (2000, p. 261) le da al término "progresista": “...como opuesto a conservador, vale decir, para calificar a algo o a alguien que apuesta o aboga por el cambio". Es decir, entiendo como "progresistas" a aquellas personas que se muestran permeables, e incluso que promueven, los cambios socio-culturales e históricos en una sociedad determinada.

Horizontes Antropológicos, Porto Alegre, ano 23, n. 47, p. 227-258, jan./abr. 2017 


\section{Relaciones erótico-amorosas}

Después de unos meses de construcción masculina, y luego de un encuentro organizado por personas trans en Bahía Blanca, Facundo comenzó una relación con Gabi, un chico trans. Al poco tiempo de frecuentarse, lo presentó a su familia como su novio, cuya elocuente reacción fue: “¿Para qué hiciste tu transición si ahora igual te gustan los hombres?"

Esa reacción por parte de su familia, decodificada desde la perspectiva heteronormativa, también fue experimentada por Julián, en esa oportunidad a su favor, puesto que sus padres, quienes siempre habían repudiado y combatido su atracción por las mujeres, ${ }^{18}$ accedieron a darle la garantía de su casa para que él pudiera alquilar un departamento cuando se fue a vivir con Soledad, su actual pareja. El razonamiento de sus padres se basaba en que si Soledad tenía un hijo de un año, debía ser una amiga y no su pareja, porque el niño era la evidencia de que le gustaban los hombres. Lo que sus padres desconocían es que Soledad veía a Julián como su pareja masculina. Porque como dijera Fausto-Sterling (2006) concebir a alguien como varón o mujer es una decisión social, no biológica ni científica.

Me interesa recuperar y detenerme en las consideraciones y en los razonamientos que tuvieron ambas familias, y sostener las tensiones y las vacilaciones que se presentan en derredor, respecto de cómo se articula el género (o la identidad de género) y el deseo sexual.

Como dan cuenta las historias de mis informantes, los cuerpos del deseo no son necesariamente los cuerpos opuestos, no es 'lo cóncavo y lo convexo' de la lírica musical (Toro-Alfonso, 2007, p. 152) sino que pueden acercarse cuerpos iguales (con vagina) que se sienten atraídos sexualmente, por el simple placer de la subjetividad compartida.

Estas formas de relacionamiento van en contra de lo que se conoce como la complementariedad sexual entre hombres y mujeres vinculándolos como opuestos complementarios a partir de una desigualdad teorizada como natural.

Justamente Parker (1999) tematiza la diversidad de las relaciones entre los géneros y los diversos significados que las diferentes culturas le asignan a

${ }^{18}$ Cuando los padres de Julián descubrieron que le gustaban las mujeres primero lo mandaron a hacer una terapia "reparativa" con un psicólogo con el objetivo de curarlo, quien trató de inculcarle modales femeninos de comportamiento. Y luego, cuando vieron que no desistía de su atracción por las mujeres y además comenzaba a expresar el género masculino le sugirieron que se fuera de su casa.

Horizontes Antropológicos, Porto Alegre, ano 23, n. 47, p. 227-258, jan./abr. 2017 
lo sexual. En esa línea señala que no se trata de concebir la sexualidad puesta en relación con el género, sino más bien de comprender la complejidad que reviste los significados de la sexualidad en cada contexto cultural.

Sin duda, en tanto somos sujetos sexuados, el deseo se inserta en el cuerpo que construimos. Las variedades y las variabilidades de la sexualidad nos indican de la complejidad del deseo y, sobre todo, pone en evidencia cómo el cuerpo construye el deseo y lo articula de formas diferentes. Esto equivale a decir que el deseo no viene determinado ni siquiera condicionado por el género, sino que es producto de las interacciones sociales y de los significados que le otorgamos socialmente (Weeks, 1995).

En el caso de Facundo la interpretación atada a la norma le significó una impugnación a su deseo por parte de su familia mientras que a Julián le funcionó como una ventaja para conseguir la aprobación y la ayuda de la suya. Sin embargo, en ambos casos se pone de manifiesto la invisibilidad de ellos como personas trans masculinas.

Biografías como éstas dan cuenta de experiencias liminales que, de acuerdo desde el lugar desde donde se las mire, bien pueden ser leídas e interpretadas como de mujeres lesbianas o bien como de masculinidades femeninas porque la disputa se da a partir de la tensión entre los marcos de la sexualidad y la identidad de género (Valentine, 2007, p. 155).

Y si bien es cierto que las transmasculinidades han sido incluidas en la historia lesbiana muchas veces erróneamente, también es verdad que, como vimos en las trayectorias de Esteban y de Facundo, algunas transmasculinidades comienzan su camino de transformación como lesbianas, atraviesan esa experiencia y la viven como una suerte de refugio temporal (Halberstam, 2008, p. 175) en su devenir trans (Preciado, 2008), aunque tantos otros no lo hagan.

De allí que, en algunas ocasiones, las distinciones entre algunas expresiones transmasculinas y algunas identidades lesbianas suelen ser difusas desde una mirada ajena. Sobre esos espacios liminales, Julián se refirió a una situación que atravesó cuando participaba de una organización de lesbianas junto a su pareja. Debido a un episodio de discriminación en un natatorio, presentó una denuncia que fue respaldada por su organización donde al redactar el escrito suscribieron "discriminada por lesbiana". Ante eso, él expresó ante sus compañeras que no se identificaba como una lesbiana sino más bien como una persona trans masculina, y esa confesión desencadenó una discusión hacia adentro de la propia organización en torno de si debía o no seguir formando 
parte. "Yo les pedí que me dejaran quedarme, porque a mí siempre me habían expulsado de todos lados: de mi casa, de la iglesia, del grupo de amigos...Y aunque no me autoidentificara como una lesbiana ahí había encontrado por primera vez un lugar donde me sentía cómodo". Sin embargo, eso no fue suficiente para que lo dejaran seguir participando en ese colectivo.

Experiencias como la de Julián ponen en evidencia cómo ciertas expresiones transmasculinas dentro de ciertos contextos lesbianos plantean un problema cuando se vuelve algo demasiado "real" o cuando se cruzan ciertas líneas imaginarias (Halberstam, 2008, p. 175).

Aquí se pone en juego lo que Rubin (1989) caracteriza como la "guerra de fronteras"19 donde, además de las luchas legales o las disputas por las definiciones existen micro conflictos político-sexuales que se desencadenan en torno de la naturaleza y los territorios legítimos o ilegítimos respecto de las identidades, los cuerpos y las sexualidades.

De allí, y luego de haber hecho trabajo de campo con personas trans en general, y en lo que concierne a este capítulo en interacción con transmasculinidades en particular, lejos de centrarme en los sistemas de clasificaciones que persiguen el propósito de otorgar legibilidad (y legitimidad) a ciertas identidades, cuerpos y prácticas sociales sobre la base de la pregunta qué es quién y cómo debe en consecuencia actuar y/ o vincularse con los demás, me interesa la manera en que cada sujeto en particular se nombra y se autoidentifica como una manera de ganar y ocupar ciertos espacios (Halberstam, 2008), táctica fundamental dentro del proceso de visibilización.

\section{Expresiones y vivencias de la masculinidad}

Con el propósito de analizar qué aspectos se muestran y enfatizan y cuáles otros se ocultan y se disimulan en el proceso del devenir trans, observé que algunas transmasculinidades hacen uso de fajas o blinder $^{20}$ para ocultar ciertas marcas corporales femeninas, sin embargo, esto no implica que no pretendan adecuar su imagen a una representación dominante de lo masculino. Por otro

19 Este concepto es retomado por Jack Halberstam (2008).

${ }^{20}$ Las fajas, los blinders o las vendas elásticas son artilugios que las transmasculinidades emplean para disimular sus pechos. En Argentina, se emplean más comúnmente las fajas torácicas al ser más accesibles que los blinder ya que, al ser un producto importado, no se consigue tan fácilmente y sus costos son más elevados.

Horizontes Antropológicos, Porto Alegre, ano 23, n. 47, p. 227-258, jan./abr. 2017 
lado, algunos otros no se hormonizan -como es el caso de Julián- ni están dispuestos a someterse a ningún tipo de cirugías como la mastectomía, por ejemplo. Asimismo, otros eligen presentarse ante los demás a partir de expresiones ambiguas y/o hasta proyectan la idea de llevar adelante un embarazo, haciendo uso de las posibilidades que le brinda su cuerpo, como es el caso de Facundo, por ejemplo.

Mientras otros, tal como han manifestado Lucas y Esteban -quienes se autoidentifican, como mostré, en principio sin la alusión a lo trans- se esfuerzan por pasar desapercibidos, disimulando todo rasgo que los vincule con lo femenino, teniendo como ideal alcanzar una imagen corporal lo más cercana posible al estereotipo masculino, y desean -aunque saben que es una intervención quirúrgica muy compleja y poco exitosa en lo que concierne al placer sexual- practicarse una faloplastía. ${ }^{21}$

Y si bien mi propósito en este capítulo no es abordar ni profundizar sobre la construcción de la transmasculinidad a partir de las prácticas de intervención corporal, estos matices entre las personas transmasculinas y sus modos de subjetivación y presentación ante los demás resultan datos que nos permiten observar el abanico diverso y complejo de expresiones masculinas.

Pero no sólo eso. Esa multiplicidad de expresiones también es lo que torna muchas veces, ininteligible la transmasculinidad. Puesto que, de acuerdo a los relatos de mis informantes, la persona transmasculina se hace visible ante la mirada de los otros sólo si se logra una masculinidad moldeada por la cultura hegemónica, poniendo en cuestión -y ubicando en la invisibilidad- las experiencias de otras masculinidades (Halberstam, 2008, p. 168). Es decir, mientras que se visibiliza lo masculino dominante se invisibiliza lo trans. Esta invisibilidad en tanto persona trans, sus ventajas y desventajas es lo que me propongo problematizar en los apartados que siguen.

\section{De ciencia ficción}

Una idea recurrente que circula entre mis informantes transmasculinos es la de sentirse invisibles. Esa invisibilidad tiene que ver con no ser reconocidos como masculinidades -alternativas a la hegemónica (Connell1, 1995) si

${ }^{21}$ La faloplastía es la intervención quirúrgica mediante la cual se reconstruyen los genitales masculinos en un cuerpo que ha nacido con genitales femeninos. 
se quiere- y ser confundidos, en ocasiones, con lesbianas butch (Halberstam, 2008) ${ }^{22}$ o simplemente considerados hombre bio (Preciado, 2008).

Incluso, si nos remontamos al capítulo donde tematizamos las representaciones dominantes sobre el universo trans, encontramos que fue recién en el 2009 cuando se tematizó en los medios de comunicación sobre la existencia de la transmasculinidad en la Argentina a partir de la aparición de Alex en el programa "Transformaciones", mientras que, por ejemplo, las travestis ya estaban en la pantalla argentina desde principio de los años '90 y en el imaginario social desde algunas décadas atrás. Y si bien parte de ese sentirse invisibles tiene que ver con que se les note menos que a una persona transfemina lo cierto es que se sabe poco -o casi nada- sobre su existencia.

Esteban cuenta, por ejemplo, que cuando empezó a salir con Candela, su actual novia, a la madre de ella le costó aceptar esa relación dado que su hija nunca había manifestado "atracción por las mujeres". Pero ese no fue el problema mayor para él dado que con el correr del tiempo -y al ver cómo se querían y cómo fue prosperando esa relación- la madre lo fue aceptando. Sin embargo, la tensión que persiste aún hoy gira en torno de no reconocer a Esteban como un hombre -como él se autoidentifica- sino más bien considerarlo una lesbiana, hecho que le recuerda constantemente llamándolo por su nombre femenino. Y pese a las constantes explicaciones que le brinda él respecto a su identidad masculina, ella sostiene que "una cosa es aceptar una relación homosexual, y otra cosa distinta es sostener el hecho de que él se crea un hombre".

Cuando recién comenzaba su proceso de transición y aún no tenía rasgos físicos masculinos predominantes, Facundo hizo una presentación -acompañado por Juana de Arco, organización feminista donde en ese momento militaba - ante la Universidad del Comahue ${ }^{23}$ con el propósito de que se reconociera su identidad masculina y se modificaran sus datos registrales hacia dentro de la Institución. ${ }^{24}$ Pese a que la resolución fue aprobada, él se vio

22 Si bien las definiciones y los estereotipos sobre butch varían incluso dentro de la misma comunidad de gays y lesbianas, las lesbianas butch tienden a identificarse más con la masculinidad en contraposición a las lesbianas femme que se identifican con lo femenino. Esto no implica, como se piensa corrientemente, que una pareja de lesbianas está siempre conformada por una lesbiana femme y una lesbiana butch.

23 La Universidad Nacional del Comahue está ubicada en la zona de la Patagonia Argentina.

${ }^{24}$ Esta presentación fue necesaria porque aún no había sido sancionada la Ley $\mathrm{N}^{\circ} 26.743$, conocida como la Ley de Identidad de Género, sancionada el 9 de mayo de 2012 en la Argentina.

Horizontes Antropológicos, Porto Alegre, ano 23, n. 47, p. 227-258, jan./abr. 2017 
obligado a pedirle a algunos profesores que ofrecían resistencia a su identidad de género a que, al menos, sólo lo llamaran por su apellido. Cuenta Facundo que algunas explicaciones que le dieron los/as profesores/as sobre la negativa a nombrarlo como Facundo fueron: ¿Cómo voy a llamarte en masculino si ni siquiera tenés apariencia de hombre? En otras oportunidades, y con aquellos profesores que tenía más confianza, al finalizar la materia, ellos se animaron a consultarle hacia donde iban sus deseos de transicionar puesto que, a partir de sus propias interpretaciones, lo confundían con una transexual femenina. Ante esa confusión, Facundo les explicaba que además de las travestis y transexuales que transicionan hacia la feminidad (MTF) existen personas como él que transicionan hacia la masculinidad (FTM) ${ }^{25}$

Esta dificultad para imaginar que hay personas que habiendo nacido con un cuerpo sexuado (Fausto-Sterling, 2006) femenino se construyen identificándose con la masculinidad se traduce en algo que me dijo Damián, cuando fui al estreno de su obra de teatro "Color Magenta" en alguno de nuestros encuentros: "Somos de ciencia ficción, la gente no sólo no sabe que existimos sino que ni siquiera puede imaginarnos".

Ese total desconocimiento se manifiesta, inclusive, en las instituciones médicas. Cuando Damián estaba a punto de ingresar a un nuevo trabajo, y le estaban haciendo los estudios correspondientes al preocupacional creyó que iba a tener que contar su historia, y como consecuencia perdería la posibilidad de ser tomado para ese tuvo ningún problema. Pero cuando la médica clínica le informó que iban a practicarle un electrocardiograma (ECG) y una radiografía de tórax (RXT) creyó que no zafaba. Al momento del ECG la médica le pidió que se recostara en la camilla y se abriera toda la camisa para colocarle las ventosas, y si bien esa situación lo paralizó, se esforzó por hacer que no pasaba nada. Peor aún fue en la RXT puesto que la técnica de rayos le pidió que se desvistiera y se ubicara de perfil con el torso desnudo frente a la máquina hasta que ella tomara las placas correspondientes. En ese momento se debatió entre confesar su condición trans o arriesgarse a ver qué pasaba. Porque si bien él reconoce que casi no tiene busto, al ver su pecho advertirían que tenía algo raro en las mamas. ${ }^{26}$

${ }_{25}$ Con estas siglas se conoce a la transición de Male to Female (MTF) y Female to Male (FTM).

${ }^{26}$ Cuando Damián atravesó esa experiencia aún no se había realizado una mastectomía. 
Después de haber atravesado esas dos experiencias Damián afirma que en las dos situaciones había "zafado" porque ninguna de las dos médicas sabía qué tenía enfrente, dado que ni siquiera quienes trabajan en el ámbito de la salud -salvo algunas excepciones- saben de estas experiencias transmasculinas, y habrán pensado, considera él, que sufría de ginecomastia. ${ }^{27}$

Esto me ha llevado a preguntarme: ¿Serán los exámenes médicos o las pruebas científicas de reconocimiento las que definen y certifican el género de una persona o el sentir personal y la autopercepción de cada quien? ¿Qué es lo que define a una persona como femenina o masculina? ¿El pene, la vagina, las gónadas, los cromosomas, la función reproductiva?

Tal como postula Fausto-Sterling (2006) el sexo de un cuerpo es demasiado complejo: "no hay blanco o negro sino grados de diferencia". ¿Acaso la certeza de ser de uno u otro sexo no termina siendo una ficción somática y tecno política? (Preciado, 2002, 2008).

Estos relatos biográficos me permiten observar cómo se va tramando 'la diferencia' a partir del vínculo entre el sexo anatómico y el género. En esta línea, es oportuna la pregunta respecto de si los hombres y las mujeres están sobredeterminados y sobredeterminados (por la biología) o indeterminados e indeterminadas (por la cultura) (Badinter, 1993).

Parto de considerar que el cuerpo es la primera diferencia incontrovertible de la diferencia humana (Lamas, 2002, p. 56). La materialidad del sexo biológico resulta un hecho innegable, pero lo que allí está en juego es la manera en cómo simbolizamos la diferencia sexual, es decir, las características que le atribuye cada sociedad a 'lo femenino' y a 'lo masculino'. O, dicho de otra manera, qué actividades, conductas y esferas de la vida le son propias a cada sexo.

Esta simbolización cultural de la diferencia anatómica va tomando forma en un conjunto de prácticas, ideas, discursos y representaciones sociales que moldean la conducta objetiva y subjetiva de las personas al tiempo que influye y produce efectos en el imaginario social respecto a cómo debe ser un hombre y cómo debe ser una mujer.

Esto se pone en evidencia, por ejemplo, en el no reconocimiento de Esteban y de Facundo como masculinidades, por ejemplo, dado que, como

${ }^{27}$ Ginecomastía es el agrandamiento patológico de una o de las dos glándulas mamarias en el hombre. Este trastorno puede ser causado por una hiperprolactinemia (exceso de prolactina en sangre) o también por un hiperestrogenismo derivado de una patología hepática como la cirrosis, por ejemplo.

Horizontes Antropológicos, Porto Alegre, ano 23, n. 47, p. 227-258, jan./abr. 2017 
ambos estaban en un período muy inicial del proceso de transformación aún no tenían $-\mathrm{y} / \mathrm{o}$ tal vez nunca tengan por decisión propia- aquellos rasgos característicos que remiten a la imagen masculina dominante.

La naturalización de dicha imagen dominante es la consecuencia del trabajo eficaz realizado a lo largo del tiempo y de manera conjunta e interconectada de distintas instituciones sociales como la familia, la escuela, el Estado, la medicina, la iglesia y los medios de comunicación (Bourdieu, 1998).

Ahora bien, la pregunta es ¿Cómo son concebidas aquellas masculinidades que no se adecúan a esos parámetros masculinos dominantes? De acuerdo a lo que observé en el trabajo de campo, las transmasculinidades se presentan como masculinidades subordinadas (Connell, 1995) en el mejor de los casos, o invisibles tanto para quienes no son reconocidos como tales como para quienes pasan como varones, como es el caso de Damián o Lucas. Es en esa tensión, entre no ser reconocido como una masculinidad o pasar inadvertido, que se delinean las trayectorias de las transmasculinidades trabajadas en esta investigación.

La dificultad en la aproximación a los estudios en torno a la masculinidad -y más aún al desafío del abordaje de masculinidades alternativas a la hegemónica, como se presentan algunas transmasculinidades- es que los marcos de los que disponemos para pensarla provienen de una estructura de dominación social, económica y simbólica que tiene a los hombres como el grupo que ostenta privilegios (Bourdieu, 1998).Vale decir: nuestros conceptos y estructuras de pensamiento son a la vez fruto de un sistema de dominación masculina, cuya mayor eficacia es la de haber logrado naturalizar lo históricamente creado, esencializando lo arbitrario.

A propósito de esto, durante el trabajo de campo, escuché en varias oportunidades a las personas transfemeninas referirse a los beneficios que obtienen las personas transmasculinas como consecuencia de su transición. Beneficios en torno a su lugar en la estructura social, es decir, pasar de un lugar de sujeto (femenino) subordinado a la posición de sujeto (masculino) dominante.

Al respecto, Califia (2003), quien trabaja sobre los diferentes niveles de privilegios que los hombres y las mujeres poseen en una sociedad determina$\mathrm{da}$, sostiene que la asimetría se debe a que la masculinidad al ser un elemento privilegiado de la jerarquía de género, conlleva tanto una inestabilidad (por eso la transfeminidad se presenta como escandalosa ya que la persona renuncia a su lugar de poder) como una inaccesibilidad: de allí que el egreso sea mucho más fácil que el ingreso. 
Esto demuestra que la noción de privilegio que supuestamente ostentan las transmasculinidades siempre tienen que ser analizadas en función de las preguntas que nos hiciéramos en otro trabajo (Álvarez Broz; Rodríguez, 2014) sobre ¿Qué es lo trans en la cultura popular trans?, parafraseando a Hall (2010) a propósito de su reflexión en torno a cómo se traman los distintos clivajes de la diferencia y sus otros subordinados. ${ }^{28}$

Por otra parte, y como expusieron hace muchos años las teóricas feministas de la diferencia o los estudios de masculinidade ${ }^{29}$ las relaciones de poder no se dan sólo entre hombres y mujeres -y por ende el pasaje de un género al otro no supone un esquema simple de obtención de beneficio o pérdida de privilegios-, puesto que también se establecen jerarquías dentro de los mismos universos masculinos y femeninos.

En este caso, la masculinidad hegemónica (Connell, 1995) establece un régimen de poder que devalúa, margina, y en el caso de las trasnmasculinidades, invisibilizaa aquellos que no cumplen con este modelo o desobedecen a los cánones establecidos, haciendo que algunas masculinidades sean consideradas más validas que otras.

De allí que portar una masculinidad 'diferente' a la hegemónica, lejos de significar un pasaje a la obtención de beneficios, se traduce en una posición de desventaja en relación a los pares masculinos y de invisibilidad en cuanto al reconocimiento social.

\section{Bautismo}

Un momento bisagra en sus trayectorias de vida es el pasaje del baño de mujeres al de hombres. Ingresar a ese espacio público e íntimo a la vez implica poner en juego un repertorio de gestos, posturas corporales, prácticas y costumbres arraigadamente masculinas que ellos deben recrear para "pasar inadvertidos". Puesto que en esa "cabina de vigilancia del género" (Preciado, 2009) no hay lugar para ambigüedades, allí es necesario ajustar la imagen y

\footnotetext{
${ }^{28}$ En “¿Qué es lo negro en la cultura popular negra?” Stuart Hall (2010) reflexiona sobre cómo los hombres negros viven sus masculinidades cuando se enfrentan a otros ejes de la diferencia reclamando visibilidad sobre la base de la opresión de las mujeres negras y la feminización de los hombres negros gay.

${ }^{29}$ Gilmore (1994); Connell (1995); Kimmel (2000); Faur (2004), por mencionar algunos.
} 
sus actitudes a las representaciones dominantes masculinas y exhibir coherencia entre cuerpo y género.

El primer día que Lucas se decidió a ingresar al baño de hombres lo hizo acompañado de su hermano. Eso le daba más tranquilidad. No es que no supiera cómo desenvolverse porque desde pequeño había estado entre niños y además llevaba con él un orinador ${ }^{30}$-dispositivo ideal para este tipo de situaciones- sino que necesitaba sentirse acompañado y seguro.

Una vez allí, se colocó en un mingitorio cercano al de su hermano intentando no voltear la mirada para no levantar ninguna sospecha. "Estaba muy nervioso, aunque me esforcé por mantener la calma". Cuando se dio cuenta que nadie lo miró ni le hizo preguntas al respecto advirtió que comenzaba a "camuflarse" entre los demás hombres. En ese gesto nimio e imperceptible encontró reconocimiento de sus pares y reafirmó para sí su identidad masculina. "Estar allí y pasar como si nada significó un antes y un después en mi persona, una verdadera prueba de fuego".

Para las personas tranasmasculinas el sanitario de caballeros constituye ese territorio donde opera silenciosamente una de las más discretas y efectivas de las "tecnologías de género" (De Lauretis, 1989 apud Preciado, 2009). Y, por tanto, el desafío más severo a su habilidad para "pasar" en espacios sólo para hombres (Halberstam, 2008). Paradójicamente, el baño constituye el peor sitio posible para ser identificado como una no-varón pero, a su vez, es inseparable del placer que causa atravesar esa experiencia sin ser descubierto (Garber, 1992, p. 47).

En este sentido, la experiencia del passing (pasar) dice Girschick (2008) $)^{31}$ constituye una negociación situacional con el entorno respecto de los modos de expresar y dar a conocer, en este caso, la identidad de género de una persona. Es en esa situación de interacción, las personas transmasculinan atraviesan

\footnotetext{
${ }^{30}$ Se conoce como orinadores a algunos dispositivos que permiten a las personas que tienen vagina y que por distintos motivos (pos operatorio, ciertas disciplinas físicas, falta de disponibilidad de sanitarios adecuados, etc.) no pueden utilizar inodoro o simplemente desean orinar paradas. También es posible fabricar orinadores caseros con trozos de manguera o elementos de goma o silicona (cf. Aportes..., 2014).

31 Según el glosario del libro de Girschick, el termino pasar o passing es un concepto que significa que un individuo es aceptado en el género que él o ella presenta; también la aceptación de quién él o ella es sin cuestionar que él o ella haya sido otra cosa. La autora sostiene que también se emplea para referir a la práctica de "acomodamiento en el binario de género como varón o mujer".
} 
una situación de tensión que se trama entre el secreto y la evidencia, y lo íntimo, lo privado y lo público (Graná, 2013).

En ese "pasar" ellos desafian el sistema de "segregación urinaria" ${ }^{32}$ al cuestionar la traducción literaria de los signos "damas" y "caballeros" (Garber, 1992, p. 49). Así, es en el sanitario de caballeros donde, como intrusos, se entrometen y despliegan una serie de performances desestabilizadoras (Edelman, 1994; Garber, 1992) al binarismo cultural dentro de la producción del género.

Sobre la necesidad de obtener reconocimiento y aceptación por parte de otros hombres, es interesante recuperar lo que plantea Kimmel (1997) respecto de la relevancia que adquiere la validación homoosocial en la masculinidad, esto es, pues, la aceptación de los hombres frente a otros hombres quienes aprueban permanentemente sus habilidades y su virilidad en un juego de competencia y aprobación mutua. Es decir, la masculinidad está signada por el escrutinio de otros hombres. Son ellos quienes evalúan la pertinencia y el desempeño de lo que se entiende por masculino en los distintos espacios y prácticas cotidianas.

En el caso particular de las transmasculinidades, la experiencia de ingresar a un baño público en busca de reconocimiento del otro-referente y para reafirmar su pertenencia a un ámbito meramente masculino implica desarrollar tácticas de invisibilización en tanto persona trans. Porque allí pasar como uno más juega un papel crucial.

El film "Los muchachos no lloran"33 constituye una de las referencias ineludibles entre mis informantes. En particular, rememoran el momento en que un grupo de amigos de un poblado rural del estado de Nebraska (EEUU) descubre que Brandon "no es un chico" obligándolo a exponer su cuerpo desnudo frente a Lana, su enamorada, para evidenciar sus rastros femeninos. No es que Lana no supiera que Brandon tenía senos y vagina. Su angustia y desesperación se despertó al ver cómo la persona que amaba era humillada y ultrajada. Pero el episodio de violencia no culminó allí. Como forma de

32 Esta categoría fue acuñada por Jacques Lacan (1989), "La instancia de la letra en el inconsciente o la razón desde Freud".

${ }^{33}$ Esta película de origen estadounidense, cuyo título original es "Boys don't cry", data del año 1999, fue dirigida por Kimberly Peirce y protagonizada por Hilary Swank y ChloeSevigny. Es un film basado en la historia verídica de Brandon Teena, un joven trans que fue violado y asesinado el 31 de diciembre de 1993 por unos vecinos y amigos de Falls City (una ciudad ubicada en el estado de Nebraska, Estados Unidos) cuando descubrieron que tenía genitales femeninos. Este suceso se enmarca en lo que se conoce como "crímenes de odio", en este caso, hacia la transmasculinidad.

Horizontes Antropológicos, Porto Alegre, ano 23, n. 47, p. 227-258, jan./abr. 2017 
escarmiento por "falsear su identidad" y para reafirmar el hecho de que no era un varón, ya que portaba genitales femeninos, lo subieron a un auto, lo trasladaron a un descampado, lo golpearon ferozmente y lo sometieron a una violación. Y finalmente lo mataron. Ese trágico desenlace como consecuencia de haber sido "descubierto" se presenta como un temor recurrente en los relatos de las personas transmasculinas.

Al respecto, es necesario señalar una diferencia fundamental con las transfeminidades: si bien es probable que ellas resulten más observadas que ellos -tanto por su excentricidad, en algunos casos como por el hecho de que "se les note más" - lo cierto es que los riesgos que corren ellos por pasar como hombres no son comparables a las incomodidades que pueden atravesar ellas en los baños de mujeres. Mientras que las transfeminidades pueden sentirse incómodas ante la mirada vigilante, la risa burlona o algún tipo de comentario discriminatorio por parte de las usuarias del sanitario, ellos pueden enfrentarse a ciertas expresiones intimidatorias, reacciones violentas -incluso extremaso ataques sexuales por parte de los varones que concurren a esos sanitarios.

Por tanto, aunque se piense como lo hace Facundo que "pasar como un varón sin dar cuenta de lo trans sea un garrón”, en algunos espacios y territorios meramente masculinos como lo es el baño, la capacidad de simular permite a los sujetos manejar la información sobre su identidad sexo-genérica y constituye un recurso de protección (Pecheny, 2005, p. 134) fundamental. Lo paradójico es que en esta situación particular invisibilizarse en tanto persona trans resulta, además de un reconocimiento a la masculinidad deseada, una táctica (De Certeau, 1996) de supervivencia.

\section{Avatares laborales}

Desde que terminó la escuela secundaria, Lucas se dedica a dar clases particulares de inglés. Desde chico, estudio en distintos institutos de zona sur de la provincia de Buenos Aires, y luego completó su formación con el profesorado en Quilmes. Se promociona con cartelitos en los comercios del barrio, en Facebook, o de boca en boca entre sus conocidos.

Al preguntarle cómo se presenta ante sus alumnos/as me respondió: "sin vueltas, soy Lucas el profesor de inglés". Esta actitud de invisibilización no es otra cosa que una táctica que intenta conservar un status identitario (Boy; Brutto; Perelman, 2009) ante la presunción de que ante la develación de su 
condición trans podría estar en riesgo su trabajo. Prepara alumnos/as desde hace años para rendir sus exámenes o para refuerzo de las materias de la escuela y nunca tuvo la necesidad de aclarar su condición trans ni dar explicaciones al respecto, puesto que, hasta el momento, nunca nadie se dio cuenta ni le preguntó nada sobre su identidad.

Esto es posible, en el caso de Lucas, porque su construcción genérica tendió a incorporar ciertos marcadores de virilidad masculina y a intervenir su cuerpo según el ideal masculino (Mendieta, 2016), motivo por el cual su condición trans pasa totalmente desapercibida. Y, no necesita someterse a "pasar la prueba" de una institución medico-laboral para acceder a un empleo dado que trabaja de manera independiente.

El caso de Facundo es distinto. Como dije anteriormente, en sus interacciones cotidianas puntea lo transmarica para alejarse de la masculinidad hegemónica. Ella trabaja en un call center donde ingresó "por cupo", gracias a un convenio que tiene una federación gayfriendly con varias empresas. Mediante ese convenio la empresa se comprometió a tomar como empleados/as a un cupo de personas gays, lesbianas y trans, y a cambio recibe promoción y publicidad. Una vez que pasaron los tres meses de prueba, la efectivizaron. Sin embargo, y pese a contar -aparentemente- con los mismos beneficios que el resto de sus compañeros/as de trabajo por estar en blanco, cuando solicitó una licencia médica dado que iba a someterse a una mastectomía bilateral total ${ }^{34}$ y el postoperatorio requería de veinte días de reposo, se la negaron alegando que se trataba de una cirugía estética y no de una cuestión de salud. Y si bien él apeló a la Ley de Identidad de Género vigente ${ }^{35}$ y advirtió que iba a poner un abogado, finalmente le descontaron los días en que se ausentó de la oficina.

Esto pone en evidencia que "los avances en la ampliación de derechos no necesariamente, y no mecánicamente implican modificaciones sustantivas en la aceptación y comprensión de la sociedad civil" (Álvarez Broz;

\footnotetext{
${ }^{34}$ Una mastectomía bilateral "total" consiste en una extirpación completa de las dos mamas.

35 En el momento en que Facundo pidió la licencia y se realizó la mastectomía, los empleadores se ampararon en que el artículo $11^{\circ}$-concerniente a temas de salud- de la Ley $n^{\circ} 26.743$, conocida como Ley de Identidad de Género, no estaba reglamentado. Recién el 29 de mayo de 2015 a través del Decreto 903/2015 se reglamentó el artículo $11^{\circ}$ de la Ley que garantiza el abordaje integral a la salud de personas trans, entre otras cosas, el acceso a intervenciones quirúrgicas y tratamientos hormonales para adecuar el cuerpo a la identidad autopercibida. Esto implica que tanto el sistema de salud público, las obras sociales y prepagas deberán garantizar en forma permanente los derechos reconocidos por la ley.
}

Horizontes Antropológicos, Porto Alegre, ano 23, n. 47, p. 227-258, jan./abr. 2017 
Rodríguez, 2014) y da cuenta de "las limitaciones del derecho como factor de cambio social” (Vaggione, 2012, p. 14).

Por su parte, Damián afirma que él siempre tuvo suerte porque "no se animaron a preguntar". Cuando un amigo le comentó que estaban buscando un vigilador para trabajar por las noches en un depósito no lo dudó: necesitaba un sueldo fijo, ya tenía el documento nuevo con su identidad masculina, se estaba hormonizando ando hacía más de un año con resultados favorables -le había crecido vello facial y se había engrosado su voz- y había advertido, en varias situaciones, que ya "pasaba" como un varón. ${ }^{36}$

Después de atravesar el examen preocupacional sin problemas, ${ }^{37}$ Damián comenzó a trabajar como vigilador en un galpón de Edesur ${ }^{38}$ de lunes a viernes desde las 18 hasta las 6hs. Y si bien eran muchas horas, valoraba tener un sueldo fijo y que fuera una tarea tranquila, porque salvo algún que otro día que venían a buscar un grupo electrógeno, pasaba las doce horas en soledad, y eso le permitía aprovechar el tiempo para estudiar, leer un libro o mirar películas. Pero cuando la empresa inició los trámites en el Banco Galicia para abrirle una cuenta sueldo, dicha entidad bancaria reveló que la persona con ese número de documento figuraba con un nombre femenino - dado que Damián, antes de su transición, había tenido un plazo fijo en ese banco-. Ese develamiento le generó dudas respecto a su continuidad en la empresa y, a la vez, mucho miedo puesto que, por un lado, Damián sabía -por el amigo que lo había recomendado- que al gerente de la empresa de seguridad "no les gustaban las personas como él”, y por otro, temía que se corriera la voz de que él era un hombre trans, que pasaba muchas horas solo en el galpón y sin ninguna cámara de seguridad, y en ese contexto temía sufrir algún ataque violento o sexual. Por estos motivos, y pese a que necesitaba imperiosamente el trabajo, decidió renunciar.

Esto demuestra que aún cuando la imagen de sí no levanta sospecha sobre su condición trans, ciertas actividades o entornos laborales no son propicios ni seguros para una transmasculinidad, dado que estas personas están en desventajas en relación a sus pares masculinos en tanto están expuestos a

\footnotetext{
${ }^{36}$ En esta oportunidad utilizo la categoría "varón” justamente para remarcar el sexo anatómico.

37 Sobre esta experiencia se tematizó en el apartado anterior "Somos de ciencia ficción".

38 EDESUR es una empresa distribuidora de energía eléctrica de la República Argentina.
} 
situaciones de riesgo permanente bajo la mirada social que concibe a las masculinidades desde los parámetros de la heteronormatividad.

Justamente porque es consciente de que un día cualquiera puede ser el último día, Julián se esmera en dar lo mejor de él como profesor de química. Ya desde el primer día en que va a la casa de sus alumnos/as, consciente de que es una persona estigmatizable, ${ }^{39}$ lleva adelante la gestión del estigma (Goffman, 2006) que porta en pos de regular los grados de información sobre su persona. Por eso, se esfuerza para dar la "mejor clase de su vida", sabiendo que si advierten su secreto -en especial los adultos- puede que sea la última vez que lo llamen para tomar clases con él.

Por eso, él sabe que, como corre con desventaja, el esfuerzo debe ser doble: mi estrategia es enamorarlos, explicarles un cálculo equivalente químico y cautivarlos de tal manera que quieran que sea yo quien vuelva a explicarles lo que no entienden".. Sin embargo, esto no es suficiente, afirma Julián. El me contó una experiencia que tuvo con Federico - un alumno de una reconocida escuela técnica a quien preparó durante los seis años para rendir el examen integral que requería la institución a fin de cada año-y que cuando la madre lo vio por televisión recibiendo su DNI donde se reconocía su identidad autopercibida, ella lo llamó por teléfono, le recriminó "haberlos engañados durante años" y le dijo que nunca más su hijo tomaría clase con él. Y así fue.

Si bien la actitud de esconder información sobre su persona puede ser considerada por otros, como vimos, como un engaño, entiendo que es una manera de presentarse ante los demás en una sociedad que, pese a la sanción de una Ley que reconoce a la Identidad de Género en el marco de los Derechos Humanos, se presenta como excluyente hacia las identidades disidentes.

Tanto el caso de Damián como el de Julián dejan entrever que la invisibilización -en este caso como una persona trans- no es un estado de equilibrio o de reposo sino que implica un esfuerzo activo (Pecheny, 2005, p. 146) para preservar su secreto. Ese secreto - del que también se valen, en otras oportunidades, Lucas y Esteban en su "pasar inadvertidos" como hombres o varones sin más les permite no ser estigmatizados o discriminados, acceder a ciertos recursos, protegerse de potenciales ataques violentos, mantener un trabajo,

39 Erving Goffman (2006) establece una distinción entre aquellas personas cuyo estigma es visible y aquellas otras cuyo estigma no es evidente ante los ojos de los demás pero podría llegar a serlo.

Horizontes Antropológicos, Porto Alegre, ano 23, n. 47, p. 227-258, jan./abr. 2017 
por mencionar las ventajas más corrientes. En este sentido, la práctica del secreto puede ser pensada como una forma de resistencia (Zempleni, 1984 apud Pecheny, 2005) ante las formas de desigualación que atraviesan a las personas transmasculinas. Es así como se produce una paradoja que emana de la tensión entre la visibilidad necesaria y una invisibilidad añorada (Boy; Brutto; Perelman, 2009).

\section{Recapitulaciones}

Tal como comencé este artículo, intenté poner de relieve a lo largo de estas páginas la complejidad que reviste para una persona transmasculina el hecho de que se les note menos. Y con ello las paradojas que implica (in)visibilizarse de acuerdo a los diferentes entornos socio-espaciales, situaciones, vínculos y constreñimientos estructurales.

Como mostré, esa masculinidad que comienza a experimentarse con otros niños es hipervisibilizada socialmente y señalada por distintas instituciones -familia, escuela- sólo con el propósito de ser vigilada y sancionada cada vez que se manifiesta, tiene su recompensa en el reconocimiento entre pares.

El tránsito por el lesbianismo constituye, para algunos, un refugio donde se detienen o un pasaje hacia la construcción de la masculinidad que va alumbrando y ordenando las piezas del género y del deseo sexual, y donde se ponen en juego las fronteras entre las identificaciones (y las etiquetas) que les adjudican los demás y las autoconstrucciones que ellos mismos van experimentando en su trayecto.

Sobre la tensión entre visibilizarse como una persona trans y pasar desapercibido como un varón más, encontré que allí donde la persona transmasculina hace un uso de la información para su propio beneficio (Delgado Ruiz, 1999), radica justamente su capacidad de agencia, y que la misma no puede concebirse en términos dicotómicos como algo beneficioso o perjudicial, sino más bien debe considerarse los contextos situacionales y sus posibilidades de acción, no perdiendo de vista la complejidad de la amalgama donde se combinan reconocimiento e indiferencia, peligro y oportunidad, valoraciones y discriminaciones, ventajas y desventajas.

En este sentido, y en relación a la pregunta que orienta y estructura este trabajo de investigación, entiendo que si bien la transmasculinidad -en tanto diferencia leída en relación a la hegemónica- tiene, en ocasiones, la 
posibilidad de invisibilizarse -y pasar inadvertida- y ese gesto puede ser asociado al acceso a una posición de poder y de privilegio (Kimmel, 2000, p. 7) en otras oportunidades esa misma invisibilización es consecuencia y producto de una situación de desigualación respecto, por ejemplo a los hombres bio.

Esto me conduce a pensar que en el juego donde se produce un mismo movimiento que, por un lado, visibiliza aquellos rasgos dominantes de la masculinidad y por otro, se invisibiliza esa 'la diferencia', entendida como una masculinidad alternativa a la hegemónica (Connell, 1995), se va tramando una táctica -no siempre consciente- que les permite sobrellevar las situaciones de desventaja social, en relación a los contextos, las necesidades y las contingencias.

Por ello, entiendo que es necesario problematizar las posturas que conciben que la visibilidad es siempre algo positivo y beneficioso. Ya que, como dan cuenta las trayectorias de las transmasculinidades es necesario investigar empírica y contextualmente sus privilegios al igual que sus riesgos y desventajas.

\section{Referencias}

ALONSO, L. La mirada cualitativa en sociología: una aproximación interpretativa. Madrid: Fundamentos, 1998.

ÁlVAREZ BROZ, M.; RODRÍGUEZ, M. G. ¿Qué es lo trans en la cultura popular trans?. Papeles de Trabajo, Rosario, v. 8, n. 14, p. 92-114, 2014.

APORTES para pensar la salud de personas trans: actualizando el paradigma de los derechos humanos en salud. [S.1.]: Capicua, 2014.

BADINTER, E. XY, la identidad masculina. Bogotá: Norma, 1993.

BELLUCCI, M.; RAPISARDI, F. Alrededor de la identidad. Las luchas políticas del presente. Nueva Sociedad, n. 162, p. 40-53, 1999.

BERTAUX, D. El enfoque biográfico: su validez metodológica, sus potencialidades. Proposiciones, Santiago de Chile, v. 29, p. 1-22, 1999.

BERTAUX, D. Los relatos de vida: perspectiva etnosociológica. Barcelona: Bellaterra, 2005. 
BOURDIEU, P. La dominación masculina. Barcelona: Anagrama, 1998.

BOY, M.; BRUTTO, N.; PERELMAN, M. Visibles-invisibles. El cirujeo en la ciudad de Buenos Aires (2002-2007). In: CONGRESO DE LA ASOCIACIÓN LATINOAMERICANA DE SOCIOLOGÍA, 27./JORNADAS DE SOCIOLOGÍA DE LA UNIVERSIDAD DE BUENOS AIRES, 8., Buenos Aires, 2009. Actas..., Buenos Aires: Asociación Latinoamericana de Sociología, 2009. Disponible en: <http://www.aacademica.org/000-062/115>. Acceso en: 1 feb. 2016.

CABRAL, M. Si yo quisiera. In: BERKINS, L. (Comp.). Cumbia, copeteo y lágrimas: informe sobre la situación de las travestis, transexuales y transgéneros. Buenos Aires: Asociación de Lucha por la Identidad TravestiTransexual, 2007. p. 55-64.

CALIFIA, P. Sex changes: transgender politics. 2nd. ed. San Francisco: Cleis Press, 2003.

CASTELLS, M.; SUBIRATS, M. Mujeres y hombres: ¿un amor imposible?. Madrid: Alianza, 2007.

CONNELL, R. W. Masculinities. Sydney: Allen \& Unwin, 1995.

DE CERTEAU, M. La invencion de lo cotidiano: artes de hacer. México: Universidad Iberoamericana, 1996.

DELGADO RUIZ, M. El animal público: hacia una antropología de los espacios urbanos. Barcelona: Anagrama, 1999.

EDELMAN, L. Homographesis: essays in gay literary and cultural theory. New York: Routledge, 1994.

FAUR, E. Masculinidades y desarrollo social. Bogotá: Unicef Colombia, 2004.

FAUSTO-STERLING, A. Cuerpos sexuados: la política de género y la construcción de la sexualidad. Barcelona: Melusina, 2006.

GARBER, M. Vested interest: cross-dressing and cultural anxiety. New York: Routledge, 1992. 
GILMORE, D. Hacerse hombre: concepciones culturales de la masculinidad. Barcelona: Paidos, 1994.

GIRSCHICK, L. Transgender voices. Hanover: University Press of New England, 2008.

GOFFMAN, E. Estigma: la identidad deteriorada. Buenos Aires: Amorrortu, 2006.

GRANÁ, L. Voces que importan: producción de reconocimiento de travestis, transexuales y transgéneros en El Teje y otros enunciados públicos. 2013. Tesis (Maestría en Sociología de la Cultura y Análisis Cultural)-Instituto de Altos Estudios Sociales, Universidad Nacional de San Martín, Buenos Aires, 2013.

HALBERSTAM, J. Masculinidad femenina. Madrid: Egales, 2008.

HALL, S. Sin garantías: trayectorias y problemáticas en estudios culturales. Popayán: Envion; Lima: IEP: Instituto Pensar; Quito: Universidad Andina Simon Bolivar, 2010. p. 287-297.

KIMMEL, M. Homofobia, temor, verguenza y silencio en la identidad masculina. In: VALDÉS, T.; OLAVARRÍA, J. (Ed.). Masculinidad/es: poder y crisis. Santiago de Chile: Isis Internacional: FLACSO, 1997. p. 49-62. (Ediciones de las Mujeres $\left.n^{\circ} 24\right)$.

KIMMEL, M. The gendered society reader. New York: Oxford University Press, 2000.

LACAN, J. Escritos. Madrid: Siglo XXI, 1989.

LACOMBE, A. Dar cuenta de lo indecible. In: TRON, F.; FLORES, V. (Comp.). Chonguitas: masculinidades de niñas. Neuquen: La Mondonga Dark, 2013. p. 195-201.

LAMAS, M. Cuerpo: diferencia sexual y género. México: Taurus, 2002.

MARRADI, A. La entrevista en profundidad. In: MARRADI, A.; ARCHENTI, N.; PIOVANI, J. Metodología de las ciencias sociales. Buenos Aires: Cengage Learning Argentina, 2012. p. 191-197. 
MECCIA, E. La cuestion gay: un enfoque sociológico. Buenos Aires: Gran Aldea, 2006.

MENDIETA, L. Tránsitos identitarios: corporalidad, género y performatividad en las transmasculinidades. 2016. Tesis (Grado)-Facultad de Periodismo y Comunicación Social, Universidad Nacional de La Plata, La Plata, 2016.

MORENO, A. La invisibilidad como injusticia: estrategias del movimiento de la diversidad sexual. In: PECHENY, M.; FIGARI, C.; JONES, D. Todo sexo es politico. Buenos Aires: Libros del Zorzal, 2008. p. 217-243.

ORTNER, S. Antropología y teoría social: cultura, poder y agencia. Buenos Aires: UNSAM, 2016.

PARKER, R. Beneath the Equator: culture of desire, male homosexuality, and emerging gay communities in Brazil. New York: Routledge, 1999.

PECHENY, M. Identidades discretas. In: ARFUCH, L. (Comp.). Identidades, sujetos y subjetividades. Buenos Aires: Prometeo, 2005. p. 127-147.

PRECIADO, B. Manifiesto contra-sexual. Madrid: Opera Prima, 2002.

PRECIADO, P. B. Testo yonqui. Madrid: Espasa Calpe, 2008.

PRECIADO, P. B. Basura y género. Mear/cagar. Masculino/Femenino. Parole de Queer, p. 14-17, jun./oct. 2009. Disponible en: <https:/www.scribd.com/ fullscreen/79994784?access_key=key-1kzk7tzxrj9solcq2esc $>$. Acceso en: 1 feb. 2016.

REYGADAS, L. La apropiacion: destejiendo las redes de la desigualdad. México: Antrophos, 2008.

RUBIN, G. Reflexionando sobre el sexo: notas para una teoría radical de la sexualidad. In: VANCE, C. Placer y peligro: expolorando la sexualidad femenina. Madrid: Revolución, 1989. p. 113-190.

SENNETT, J. (Ed.). Self-organizing men. [S.1.]: Homofactus, 2006.

TORO-ALFONSO, J. Juntos pero no revueltos: cuerpo y género. Revista Puertorriqueña de Psicología, v. 18, p. 146-156, 2007. 
TRON, F.; FLORES, V. (Comp.). Chonguitas: masculinidades de niñas. Neuquen: La Mondonga Dark, 2013.

VAGGIONE, J. Prólogo. In: JONES, D.; FIGARI, C.; BARRON LOPEZ, S. La produccion de la sexualidad: polítcas y regulaciones sexuales en Argentina. Buenos Aires: Biblos, 2012. p. 9-18.

VALENTINE, D. Imagine transgender: an ethnography of a category. Durham: Duke University Press, 2007.

VIVEROS, M.; CAÑON, W. Pa bravo...yo soy candela, palo y piedra. Los quibdoseños. In: VALDÉS, T.; OLAVARRÍA, J. (Ed.). Masculinidad/es: poder y crisis. Santiago de Chile: Isis Internacional: FLACSO, 1997. p. 125138. (Ediciones de las Mujeres $n^{\circ} 24$ ).

WEEKS, J. History, desire and identities. In: GAGNON, R. P. Conceiving sexuality: approaches to sex research in a postmodern world. New York: Routledge, 1995. p. 33-50.

WILLIAMS, R. Marxismo y literatura. Barcelona: Ediciones Península, 2000.

WITTIG, M. El pensamiento heterosexual y otros ensayos. Madrid: Egales, 1992. 